Citation:

Allen-Collinson, J (2011) Feminist phenomenology and the woman in the running body, Sport, Ethics \& Philosophy, 5 (3): 287-302.

\title{
Feminist phenomenology and the woman in the running body
}

\section{Jacquelyn Allen-Collinson}

Contact:

Dr Jacquelyn Allen-Collinson

Department of Education

University of Bath

Claverton Down

Bath BA2 7AY

Tel: $\quad+44(0) 1225386912$

Email: J.Allen-Collinson@bath.ac.uk 


\begin{abstract}
Modern phenomenology, with its roots in Husserlian philosophy, has been taken up and utilised in a myriad of ways within different disciplines, but until recently has remained relatively under-used within sports studies. A corpus of sociological-phenomenological work is now beginning to develop in this domain, alongside a longer standing literature in feminist phenomenology. These specific social-phenomenological forms explore the situatedness of lived-body experience within a particular social structure. After providing a brief overview of key strands of phenomenology, this article considers some of the ways in which sociological, and particularly feminist phenomenology, might be used to analyse female sporting embodiment. For illustrative purposes, data from an autophenomenographic project on female distance running are also included, in order briefly to demonstrate the application of phenomenology within sociology, as both theoretical framework and methodological approach.
\end{abstract}




\section{Introduction}

Within sports studies, the woman in the sporting body has been studied from myriad theoretical angles over the past 30 years, including via a range of 'feminist prisms' (e.g. Hall 1996; Wearing 1998). There remains, however, a relative lacuna in relation to embodied research on the lived experiences of the sporting body from a phenomenological perspective (Hockey and Allen-Collinson 2007; Allen-Collinson 2009). Wacquant (2004) highlights a need to conduct research not only of the body (as an object of study), but also from the body - using the body as a tool of inquiry. I argue here that using a form of 'sociologised' (see below) feminist phenomenology, can provide rigorous, grounded, and insightful analyses of female sporting embodiment, and effectively portray the complexities of sporting experiences - both cognitive and corporeal. Brief data from a research project on female distance running are included for illustrative purposes only. I should emphasize that, as a sociologist, I am working within the sociological-phenomenology tradition (Schutz 1967; Psathas 1973; Katz and Csordas 2003) rather than from a philosophical base. The openness of phenomenology to different readings has been noted as one of its strengths, with 'no place for phenomenological orthodoxy, or for so-called "purism"' (Mortari and Tarozzi 2010: 9). I address here feminist-sociological phenomenology, although for ease of reading, I use the term feminist phenomenology (described below). I am thus writing as a phenomenologically-inspired sociologist.

The interaction between phenomenology and feminism has furnished powerful analytic insights (de Beauvoir 1972; Fisher 2000). This paper considers some of the possibilities offered by this nexus, which at times gives rise to scepticism and disquiet on both 'sides', but also generates potent insights in examining female experience as lived and felt in the flesh (Young 1998). The philosophical phenomenological quest to seek out 'essences', the essential structures of experience (see below), has sometimes been understood as some form of essentialist quest for universal experience, neglectful of the specificities of biological sex, and of gender and other forms of social-structural 
'situatededness'. As I consider below, feminist phenomenology addresseses such criticisms head-on by acknowledging the powerful influences and constraints of social structure upon lived experience, and the corporeal specifics of bodies that are located in time and culture.

To date, studies of sporting experience employing a phenomenological theoretical framework remain relatively under-developed (Kerry and Armour 2000; Allen-Collinson 2009), although a literature is gradually developing. The following studies provide just a flavour of this oeuvre, drawing primarily upon existential phenomenology, particularly Merleau-Ponty's work on the body as subject of perception. Masciotra et al. (2001), for example, provide a detailed, phenomenologically-grounded account of spatio-temporal distancing and co-ordination in Karate, whilst Bar-on Cohen (2006) addresses 'somatic codes' (words verbalising interior body dynamics) and pedagogy in Karate training. The dialectical relationship between 'player-body-subject' and the lived-space of the playing field is observed in football/ soccer by Hughson and Inglis (2002) and Hemphill (2005). For those researching mind-body practices and physical cultures, Merleau-Ponty has proved a fertile source. Samudra (2008) portrays kinaesthetic experiences in Silat Bangau Putih, a Chinese-Indonesian self-defense and health system. Morley (2001) examines yoga practice utilising Merleau-Pontian constructs and drawing comparisons between the practice of yoga and phenomenology itself, including epochē/bracketing (see below). Addressing sports and physical activity more generally, Hockey and AllenCollinson (2007) explore the sensory dimension of the sporting body, applying MerleauPonty's (2001) work.

The article is structured as follows. First, for those unfamiliar with the tenets of phenomenology, a basic overview is provided, before moving to sociologicalphenomenology and feminist phenomenology respectively. Phenomenology is used variously as epistemology, theoretical perspective, methodology and method (Mortari and Tarozzi 2010) and sometimes as a combination of all these. An overview of the phenomenological method is therefore also given. Briefly to illustrate its application as 
method, I then describe an autophenomenographic research project on female middle/long-distance running.

\section{The multiple strands of phenomenology}

Different ontological and epistemological positions underlie the many and complex strands of the 'tangled web of phenomenology' (Ehrich 1999: 20) and here I can only touch upon this complex, protean and nuanced perspective (see Allen-Collinson, 2009, for a recent overview in relation to sports studies). Inevitably, much of the richness and complexity is lost in such a brief resumé, and as Spiegelberg (1982) notes, there are as many styles of phenomenology as there are phenomenologists. Described as arguably the major philosophical movement of the twentieth century (Embree and Mohanty 1997: 1), phenomenology is the study of phenomena, things as they present themselves to, and are perceived in consciousness. Phenomenology as philosophy was originally developed by Husserl as a radical new approach to remedying what he considered the lamentable inadequacies of positivist scientific approaches to studying the nature of human existence. Husserl sought to reinstate the importance of the subjective dimension, arguing for the experiential basis of all knowledge. Maurice Merleau-Ponty (2001: vii), one of the key exponents of existentialist phenomenology, wrote that the question of what phenomenology actually is, had by no means been resolved. Part of the problem (if problem it is) lies perhaps in the different ontological and epistemological positions underlying the distinctive strands of phenomenology.

Embree and Mohanty (1997) posit four key strands or 'tendencies' within phenomenology: realist, transcendental constitutive, hermeneutic, and existentialist. Although there are many more forms of phenomenology, a brief description of the latter three strands, as particularly apposite to sports studies, may prove helpful. I should emphasize that what are portrayed here for heuristic purposes as distinct strands are actually overlapping; the work of some theorists transcends categories, and we could argue long as to who sits where within the phenomenological enterprise. With this firm caveat then, I portray the three tendencies as follows. 
1) Transcendental or constitutive phenomenology is grounded in Husserl's (1983 [1913]) Ideas and subsequent work. As Embree and Mohanty (1977) indicate, constitutive phenomenology relates broadly to the notion that we are simultaneously in and part of the world into which we are born. This strand is transcendental in seeking to transcend our framework of everyday, tacit presuppositions and taken-for-granted assumptions about phenomena - including 'scientific' assumptions, interpretations and abstractions. Husserl's idealist transcendental phenomenology aimed to develop a method to yield absolute essential knowledge or universal laws of facts (Jennings 1986: 1235). Transcendental phenomenology is primarily descriptive, utilising the techniques of epochē and reduction (defined below) to suspend or bracket the natural attitude, our everyday beliefs and presuppositions about a phenomenon, in order to arrive at its essences - as Husserl advocated, to return 'to the things themselves' (zu den Sachen selbst). Husserl initially sought not only the suspension of beliefs and assumptions, but also the bracketing of oneself from the 'natural world' via the transcendental reduction, in order to attain a pure transcendental consciousness. The notion of 'transcendental subjectivity' was interpreted by some as unattainably idealistic and thus subjected to mordant critique, leading Husserl to refocus his later work toward the development of a theory of intersubjectivity using the concept of the Lebenswelt - the commonsense lifeworld of everyday experience; a conception that stimulated much sociological interest. Alfred Schutz $(1967,1973)$, for example, synthesized aspects of Husserl's concept of the life-world to create a phenomenological sociology or sociological phenomenology (Wagner 1973) (see below), and inspired the radical thinking of Harold Garfinkel (1984), the originator of ethnomethodology.

In recent times, Giorgi (1985) has contributed a significant body of work within the general spirit of descriptive, empirical phenomenology, applied to psychology and adhering closely to Husserlian descriptive phenomenology. Within studies of sport and physical culture, examples of research that employ transcendental descriptive phenomenology include Morley's (2001) study of breath control in yoga, which also 
contrasts transcendental with existentialist forms of phenomenology. Moe (2004) uses both transcendental and hermeneutic phenomenology to explore processes of skill acquisition in sport.

2) Hermeneutic phenomenology focuses upon the context, intention and meaning surrounding a text or representation. Whilst transcendental phenomenology advocates a descriptive approach, hermeneutic phenomenology emphasizes the interpretive. Heidegger, whilst often characterised as an existential phenomenologist, posits that all description is always fundamentally interpretative, and argues (1962) against the possibility of our being (Sein) as open to bracketing or suspension, given its predating of, and pre-eminence over consciousness. For Heidegger (1962), humans are 'thrown into' the world, and experience it directly through a kind of encompassing sight or circumspection (Umsicht), developing a certain know-how or intuitive coping skill. Within sports studies, hermeneutic phenomenology has been employed for example by Ryba (2008), to examine young athletes' experiences of figure skating, and Breivik (2010) in relation to skydiving as a condition not of 'being-in-the-world', in a Heideggerian sense, but rather of 'being-in-the-void'.

3) Existentialist phenomenology draws upon the work of major French existentialists such as Simone de Beauvoir, Jean-Paul Sartre, and Maurice Merleau-Ponty, who wedded existentialism and phenomenology (Ehrich 1999: 28) in a powerful analytic framework. Existentialist phenomenology highlights the centrality of the body in human experience, one's own body (le corps propre) as the subject of perception, the standpoint from which the world is perceived and experienced (Merleau-Ponty 2001). This focus on embodiment - the social and cultural ways in which we live our bodies in everyday life is clearly of salience within sport sociology. Whitehead (2007), the originator of the 'physical literacy' perspective, argues that perception and bodily action form the basis of meaning, not created as a result of applying rules of cognition, but arising through our embodied interaction with the world. 
Existential phenomenologists emphasize human existential unity with the chair (flesh) of the world. In his later work, Merleau-Ponty recast the 'lived body' of his earlier writings as chair in order better 'to capture its primordial or elemental character' (Morley 2001: 75), to convey more vividly the continuity of world and body. Merleau-Ponty's (1969) focus upon the sensory dimensions of embodiment and his concept of reversibility (2001: 93) also have high applicability to sociological studies of sporting embodiment (see Hockey and Allen-Collinson 2007). Reversibility refers to the notion that our sense perceptions are reversible: we both touch and are touched, see and are seen, and so on. So Merleau-Ponty (2001: 93) suggests that the experience of touching, for example, cannot be understood without reference to the possibility of situational reversal. In relation to sportspeople, the haptic relationship is not just with other participants but also with objects and the general environment (Allen-Collinson and Hockey 2011). Importantly too, for sociological-phenomenology, existentialist phenomenology highlights the situatedness of human experience, including gendered experience and behaviour (de Beauvoir 1974; Young 1980).

\section{Sociological and feminist phenomenology}

Husserl's phenomenology was first applied extensively within North American sociology by Alfred Schutz, whose work was initially considered as phenomenological psychology given its focus upon inner, subjective experience. Subsequently, Schutz's (1967, 1973) attention turned toward the Husserlian conception of the life-world (Lebenswelt). He adapted and synthesized aspects of Husserl's thinking with Max Weber's theory of Verstehen and social action to create a phenomenological-sociology or sociologicalphenomenology (Wagner 1973), and his sociological interest was particularly sparked by Husserl's investigations into intersubjective communities. As Liberman (2009: 149) notes, Husserl's work on 'intersubjective constitution' generally was taken up enthusiastically by researchers in sociology. Another key perspective in sociologicalphenomenological thinking developed from the work of Berger and Luckmann (1966) on the social construction of reality, and the ways in which social actors jointly construct and 
sustain reality via social interaction. Berger and Luckmann examined how such 'reality' can become embedded within society and transmitted generationally, including via taken-for-granted 'common sense' knowledge. Feminist writers working from a socialconstructionist perspective have emphasized that what becomes accepted as knowledge is not necessarily a 'scientific' or indeed a neutral process, but dependent upon the power of social groups to promote their own ideas of what constitutes (or should constitute) 'reality' and counts as 'knowledge'. Much of what has been constructed as universal, human reality, and neutral, gender-free knowledge, has been challenged by feminist writers as partial, masculinist and androcentric. Such partialness might also apply to the realities of other social groups marginalised under male (heterosexual) hegemonic discourse, such as black and minority ethnic groups, for example. The feminist critique of 'traditional' (masculinist) phenomenology has been trenchant and far-reaching.

Just as there are myriad forms of phenomenology, there are similarly many and varied forms of feminism, from the materialist social-structural orientation of Marxist feminism to the linguistic constructionist perspectives of poststructuralist feminism, and beyond. In very general terms, though, feminist phenomenology allies phenomenology with the feminist theoretical focus upon the social-structural position of women in a patriarchal system of gender relations, where women as a social group are systematically disadvantaged in relation to men as a social group. Although Martín Alcoff 'take[s] it as a given that phenomenology needs feminism' (2000: 39), the nexus is not always a comfortable one. Postmodernist or poststructuralist feminist theorists, for example, with their focus upon the discursive production of subjects and subjectivities, are unlikely to embrace the material 'corporeality' of existential phenomenology. Feminists of the body, however, have engaged with the writings of existentialist phenomenologists such as de Beauvoir's and Merleau-Ponty, subjecting to mordant critique the dominance of 'reason' and the systematic denial of the role of the body (e.g. Grosz 1994). But feminists have also levelled trenchant criticisms at forms of 'traditional phenomenology' (Fisher 2000) for insufficient recognition of, and analytic attention to 'difference', including differences 
of sex, gender and sexuality, and importantly for assuming that 'male equals universal'. Butler (2006), for instance, takes to task Merleau-Ponty for his lack of specificity regarding the kinds of bodies and sexualities he analyses, and his uncritical, implicit assumption of the male body as norm; an ironic failure to bracket his own presuppositions about what is generic. Other feminist theorists (for example, Preston 1996; Fisher 2000), argue that despite undoubted lacunae in his analysis, MerleauPonty's account of the body can in fact help us grasp significant aspects of human existence that span distinctions such as class, 'race', and gender. ${ }^{1}$ Furthermore, as Fisher (2000: 25) points out, traditional phenomenology provides a good basic framework, which is then open to application to experiential specificities, such as those of women.

In relation to female embodiment, feminist phenomenology is well-placed to provide a powerful analysis of women's lived-body experience as both biologically specific, and also situated within a particular historical social structure. For feminist phenomenologists, the 'personal' of phenomenology (first-person, subjective, experientially-grounded) is fundamentally linked to the 'political' (located within wider social, political and ideological structures). De Beauvoir's (1972) analysis of the phenomenology of 'sexual difference' in The Second Sex ${ }^{2}$ provides an early example of the potent feminism/existential phenomenology nexus, combining the insights of existential phenomenology with a gender-sensitive analysis in order to address issues of female Dasein (being-in-the-world). In her ground-breaking work, de Beauvoir problematises many of the taken-for-granted assumptions of her (and our) time surrounding the 'naturalness' and biological basis of womanhood and female subjectivity. She does at some points, however, leave us with a feeling that female Dasein somehow contrasts unfavourably with its male counterpart. Such negative connotations have subsequently been explored and challenged by subsequent feminist-phenomenological

\footnotetext{
${ }^{1}$ See the collection edited by Olkowski and Weiss (2006) on feminist interpretations of Merleau-Ponty.

${ }^{2}$ A new translation of this work was published in 2009, in order to remedy the limitations of the earlier Parshley English translation,, and to reinstate large sections of the text omitted by Parshley.
} 
thinkers, and two contrasting examples drawn from phenomenological studies of women's sporting embodiment provide illustratration.

Young $(1980,1998)$ examines female bodily comportment in her paper 'Throwing like a Girl', analysing the ways in which feminine motility and spatiality are constrained within a patriarchal social structure. Young (1980: 139) critiques de Beauvoir for 'largely ignoring the situatedness of the woman's actual bodily movement and orientation to its surroundings and its world' and thus creating the impression that it is female biology, anatomy and physiology per se that are at least in part determinative of women's 'unfree' status. Revisiting 'Throwing' almost twenty years after initial publication, Young (1998) criticises her earlier work for an overemphasis on the negative aspects of female embodiment, subsequently according greater acknowledgement to female social agency. Similarly employing feminist phenomenology to strong effect, but in the realm of women's mountaineering, Chisholm (2008) emphasizes the significance of the lived body over the category of gender, and highlights women's agentic potential for transcending the constraints of the gender system via active cultivation of the body's motility. The structure-agency dialectic has also emerged as a key lived experience in analyses of female running in the gendered domain of 'public' space (Allen-Collinson 2010).

Sociological-phenomenology and feminist phenomenology thus add a powerful additional analytic element to more 'traditional' phenomenology in explicitly acknowledging and theorising the historically-specific, social-structurally elements of human experience and embodiment, and the specifics of bodies that are gendered, 'raced', aged, with varying degrees of dis/ability, and so on. Sociological-phenomenology sharpens the focus upon our corporeal embeddedness within cultural and social worlds. In this vein, Csordas' (2002: 244) concept of 'somatic modes of attention' is apposite to sociological-phenomenological research on sporting embodiment in its focus upon the 'culturally elaborated ways of attending to and with one's body in surroundings that include the embodied presence of others'. I now consider: i) the application of 
phenomenology in studies of sport and physical cultures; and ii) the principles of the phenomenological method.

\section{Phenomenology and sporting embodiment}

To illustrate phenomenology's distinctiveness in portraying sporting experience, an exemplar drawn from Kerry and Armour (2000: 3-4) is helpful. Employing the example of glycogen depletion or 'hitting the wall' in distance running, the authors contrast a phenomenological and a physiological approach, where the latter seeks to hold constant certain variables whilst manipulating others in order to ascertain whether some distinctive, 'objective' bodily process is occurring. Phenomenologists, in contrast, endeavour to capture as far as possible the subjective experience and meaning of hitting the wall, irrespective of whether 'the wall' exists in any 'objective', physiological, cellular sense. Phenomenology has long been concerned with embodiment issues, and with experiences and meanings of sport, exercise and movement (Arnold 1979). Given his interest in embodied consciousness, perception, intentionality (see below), and the ways in which we experience lived time-space, Merleau-Ponty's phenomenology has been utilised to great effect in the phenomenological analysis of various sports and physical cultures, as highlighted above.

In relation to embodiment and the development of sporting skills and capabilities, drawing on Merleau-Pontian perspectives, Crossley (2001: 123) portrays the corporeal schema as: 'an incorporated bodily know-how and practical sense; a perspectival grasp upon the world from the "point of view" of the body'. For sportspeople, such corporeal know-how is developed via socialisation into specific training practices, so that the sporting 'habit-body' requires not only a cognitive understanding of its tasks, but also develops corporeally embedded knowledge and memory. Crossley (2001) distinguishes between what we might conceptualise as two 'layers': that of the 'habit-body' and that of the 'body-at-this-moment'. The habit-body transcends the immediate ground of spontaneous sensation of the-body-at-this-moment, absorbed in its immediate 
environment, and persists over time, allowing us to perceive the world around. The embodied knowledge and memory of the sporting habit-body are developed and become sedimented over time via habitual, everyday training practices, as portrayed for example in rugby (Pringle 2009), cricket (Sutton 2007), boxing (Wacquant 2004), and martial arts (Samudra 2008). Phenomenology elucidates the ways in which the development of such skill and expertise requires sports participants to move beyond the cognitive, to develop a seemingly 'natural', pre-reflective, embodied response to situations. Interestingly too, the very lack of such 'naturalness' has been highlighted by phenomenological writers. Preston (1996) addresses what we might term the 'non-habit body', using Young's (1998) example of some women's lack of habituation in relation to athletic practices. 'Throwing like a girl' is thus viewed not so much as a property of 'like-a-girlness' but rather about engaging in unfamiliar, non-habitual practices.

In general then, how might phenomenologically-inspired sociological researchers approach the task of investigating sporting practices and experiences? The next section considers the phenomenological method itself, and the relatively novel approach of 'autophenomenography' (Gruppetta 2004; Allen-Collinson 2011). Phenomenology's focus upon the subjective dimension, and use of first-person accounts of lived experience and meaning, has resulted in its sometimes being erroneously conflated with qualitative research in general, without acknowledgement of its very distinctive philosophical heritage.

\section{Notes on the phenomenological method and autophenomenography}

In general, phenomenologically-inspired researchers within the social sciences assemble highly detailed, in-depth descriptions of subjective experience in specific contexts, and seek to identify their 'essences' (described below); the essential, but (for sociologicalphenomenologists in particular) always situated patterns or 'structures' of experience as they appear to consciousness. Although the different strands of phenomenology have their own distinctive principles and perspectives, four themes or qualities, derived from 
Husserlian phenomenology, provide a touchstone in portraying 'the phenomenologcal method'. This, it should be emphasized, is not method in terms of a set of specific research techniques or procedures, but much more: an encompassing attitude, a whole orientation to the world, requiring, as van Manen (2000) advocates, a certain attentive awareness to the things of the world as we live them rather than as we more abstractly theorize them. We might describe the phenomenological method as an attitude of wonderment, an attempt to see the world through fresh, 'naive' eyes. Any tight prescription of method(s) would run counter to the openness of this phenomenological enterprise. Indeed, a whole range of methods-related questions is regularly discussed and debated intra and inter the strands of phenomenology (see Finlay 2009). A brief explanation of the four characteristics provides context for those unfamiliar with this methodological approach: 1) description; 2) epochē and reduction; 3) essences; and 4) intentionality.

\section{1) Description}

Given the centrality of the inter-relationship between the perceiver's consciousness and perceived objects, phenomenological description is never viewed merely as the 'abstract' writing or recording of things without reference to the perceiver/researcher. Description, however, can mean very different things for phenomenologists of different traditions. For hermeneutic phenomenologists and indeed for most sociologicalphenomenologists, there is no description without interpretation, for any description provides: 'not a copy of the world, but a hermeneutics' (Spurling, 1977: 168). Forms of Husserlian transcendental phenomenology, on the other hand, aspire to describe a phenomenon by suspending as far as possible prior knowledge, assumptions, attitudes and interpretations enveloping it, in order to arrive at its essential core meanings. This is undertaken via the processes of epochē and reduction.

\section{2) Epochē and reduction}

These concepts have been subject to intense contestation and Husserl himself never precisely defined what these processes were; phenomenological researchers employ the 
terms in a plethora of ways (Gearing 2004). The notion of 'epochē', from the Greek to abstain, stop, or keep a distance from, dates back to the ancient Skeptics and was used by Husserl to denote the attempt to suspend all taken-for-granted assumptions and presuppositions about a phenomenon. The skeptical epochē is a process, 'which places in question all [the philosopher's] hitherto existing convictions, which forbids in advance any judgmental use of them, forbids taking any position as to their validity or invalidity' (Husserl 1970: 76). It is thus the suspending or temporary bracketing ${ }^{3}$ of the 'natural attitude', our taken-for-granted, everyday assumptions about a phenomenon, including 'scientific' abstractions, in order to arrive at and describe its essential characteristics, to be faithful to the thing itself.

For Husserl, once the natural attitude has been suspended via the first stage of epochē, eidetic reduction was used to make sense of what remained, to reduce the phenomenon to an exemplar of an essence or an eidos. This, for him, required a further level of reduction, the transcendental reduction to the 'absolutely unique, ultimately functioning ego' (Husserl 1970: 186), and thus to transcendental subjectivity. For sociological-phenomenological researchers, we depart from Husserl's thinking at this point, for complete bracketing of the socio-cultural situatedness of our descriptions and understandings is acknowledged to be an impossibility; we cannot stand outside our cultural frame of reference (including our language structures). What is useful to us, however, is the exhortation to make best efforts reflexively and systematically to be aware of our assumptions and standpoints, and to render these explicit. In sports studies for instance, it is possible to take the descriptions provided by participants themselves and subject these to analysis by bracketing as far as possible our prior assumptions regarding the phenomenon, for example by making the familiar strange, explicitly recording and critically questioning our own conceptualisations of the

3 Although there are nuanced differences of meaning between the terms epochē and bracketing, they are often used synonymously and interchangeably to refer to the change in attitude necessary for philosophical inquiry. Following Gearing (2004), and for the purposes of this article, I use the terms epochē and bracketing as synonyms, whilst cognisant that this is by no means accepted practice across phenomenological traditions. 
phenomenon, or using researcher triangulation. Methods of bracketing utilised in a recent research project on women's running are considered below.

\section{3) Essences}

The purpose of Husserl's phenomenological reduction is to distil a phenomenon, to reduce it to its eidos, devoid of the usual tacit, taken-for-granted assumptions enveloping it. For Husserl (1970), a central aim of phenomenology was the discovery of the essential patterns or structures of an experience, in order to create a systematic and disciplined methodology for the derivation of knowledge. But, as Ehrich (1999: 23) emphasizes, for later phenomenologists such as Merleau-Ponty, arriving at such description is not the culmination, but merely a starting point in seeking to understand the experience. The concept of 'essences' has been widely debated, particularly in relation to notions of universality and the independence of essences from social context. For sociologicalphenomenologists, the emphasis is on the situatedness of experience so that essences are acknowledged to be socially constituted, culture- and context-bound. For us, the essence coheres around the recognition of generalities in the phenomenon, rather than making a definitive statement about its invariance.

\section{4) Intentionality}

Intentionality is the notion that consciousness is always consciousness of something; it is thus intentional, orientated towards something/someone. As Willig (2008: 52) neatly phrases it: 'Intentionality allows objects to appear as phenomena', and explains why different people experience the 'same' thing in sometimes radically different ways. So, if whilst out running I think I see a snake in the grass, then I have a 'snake-in-the-grass' experience, whether or not the snake is actually 'real'. Merleau-Ponty (2001) distinguishes between two kinds of intentionality: intentionality of acts, when we consciously and voluntarily take up a position; and operative intentionality, a kind of prereflective intentionality, a background-noise setting to our lives, only brought to light via the reduction (see Reuter, 1999 for a concise explanation). Whilst Husserl focussed upon the intentionality of mind, Merleau-Ponty (2001) highlights bodily intentionality - the body as an attitude directed toward an existing or potential task. For him, intentionality, 
perception and action are fundamentally intertwined; all elements apposite to sociological-phenomenological analyses of sporting experiences.

These, then, are four key elements in the Husserlian phenomenological method, subsequently developed and revised within different forms of phenomenology. For many sociological-phenomenologists, any research method able to generate detailed descriptions of participants' concrete lived experiences of a phenomenon, can provide data for the application of phenomenologically-inspired analysis. Phenomenological researchers in the social sciences have, however, sometimes found themselves subject to criticism for non-participation in the phenomenon/a under study, as Gruppetta (2004) points out. Although a phenomenological researcher's use of second-hand accounts need not necessarily be construed as a weakness of method, autoethnographic phenomenology or 'autophenomenography' provides an interesting avenue for addressing such criticism.

Gruppetta (2004) and Allen-Collinson (2009), working from within social-scientific forms of phenomenology, contend that if an autoethnographic researcher analyzes her/his own experiences of a phenomenon rather than of a 'cultural place' - as in autoethnography - then an appropriate term would be 'autophenomenography'. Autophenomenography is thus an autobiographical genre in which the phenomenological researcher is both researcher and participant in her/study of a particular phenomenon, subjecting her/his own lived experience to sustained and rigorous phenomenological analysis (Allen-Collinson 2011). Here it should be noted that I choose the term 'autophenomenography' rather than 'autophenomenology' for two reasons. First, as with ethnography and its offspring, autoethnography, 'graphy' is taken to delineate the research process as well as the written or other representational product of that process. Second, autophenomenology has specific - and contested - meanings within phenomenology (see for example, Drummond 2007; Marbach 2007) and there is not the scope here to delve into these debates. Briefly to 'ground' the article with some data, I include below details of a recent autophenomenographic research project on female distance running. 


\section{The Research}

To contextualise the research, whilst falling firmly within the non-élite category, I am highly committed, a 'serious runner' whose running encompasses two of Bale's (2004) forms: 1) welfare running, pursued for health and fitness aims; and also 2) performance running, pursued in order to improve and sustain performance. Although 'performance' is usually employed in relation to élite athletes, elements can usefully be applied to 'serious runners', who: 'regularly [run] further and faster than fitness for health would demand' (Smith 2000: 190). As part of an autophenomenographic project on middle/long-distance running, I maintained a research log for a period of 2.5 years (ongoing), which includes highly detailed descriptions of my subjective and corporeal experiences during training sessions.

The research adheres to Giorgi's (1985, 1997) descriptive, empiricalphenomenological guidelines, and includes the following elements: i) the collection of concrete descriptions of phenomena from an 'insider' perspective; ii) the adoption of the phenomenological attitude; iii) initial impressionistic readings of the descriptions to gain a feel for the whole; iv) in-depth re-reading of these descriptions as part of a process of data-immersion, to identify themes and sub-themes; and $v$ ) the production of accounts of the essential structure(s) of the experiences. Given the ideographic nature of the research, I depart at this juncture from Giorgi's method with regard to constructing general descriptions across a range of participants. Instead, the focus is upon my own lived experiences of a phenomenon.

A 23-year career in running gives me some confidence of fulfilling Garfinkel's (2002) phenomenologically-derived 'unique adequacy requirement' for the analyst to be familiar with the phenomenon. This requirement of familiarity can, however, render problematic another key element of the phenomenological method, epochē, thus requiring heightened reflexivity of the 'insider' researcher. In order to bracket (in a sociological-phenomenological sense) my own preconceptions about female running in public space, I engaged in two bracketing practices to make the familiar strange: 1) 
discussions with both insiders and non-insiders to the distance-running subculture, female and male; 2) in-depth reading of ethnographic accounts of other sporting activities in order to compare and contrast the key elements of these with the running experience. Whilst straying from Husserl's idealistic notion of epochē, this process did challenge my 'fore-conceptions' and increase reflexivity by identifying many tacit assumptions. I now portray an instance from the data, which demonstrates feministphenomenological analysis of a lived experience of danger.

As context, the majority of my training currently takes place as a solo female runner in public space. Feminist writers have long identified the gendered nature of space, including the dangers to women moving in and through 'public' space (e.g. Valentine 1989). My running in public space is thus lived and felt at the individual, subjective level, but is also deeply structurally-shaped by my difficulty, as a woman, in securing 'an undisputed right' to occupy that space (Hanmer and Saunders 1984). Running in public space can render women -and men also - vulnerable to verbal and physical harassment, even assault, and there appears to be a strongly gendered element to this harassment (Smith 2000).

Over the years, I have been subject to varying degrees of verbal and physical harassment; men/teenage boys have lunged and grabbed at various parts of my anatomy. The embodied consequences of such abuse and attack mean that at times when corporeal vulnerability is brought forcibly to the forefront of my consciousness, I run warily, eyes and ears on full alert, breath at times shallow so that I can better listen for sounds. My running body is no longer the running habit-body, at ease with itself and the environment, but is brought vividly and jarringly to consciousness. My bodily intentionality is also redirected from other important running elements, such as the terrain underfoot, 'obstacles' such as pedestrians and cars, to potential or actual attackers. A log entry testifies to some key phenomenological elements: intentionality, the mind-body nexus, and problems of bracketing, in relation to an incident that turned out to be relatively innocuous, but due to my intentionality was initially experienced as highly threatening. 
Phew, strange run tonight. Out along the river meadows quite some way from the city and approaching the weir. Suddenly out of the blue, a red pick-up truck is hurtling its way across the field towards me down the track toward the river. I had spotted the truck previously careering across the fields, but within sight and earshot of dog-walkers and others, I had paid it little heed. Now there is no one in sight, and the houses bordering the river are some way off on the other bank. Is that a shot gun sticking out of the open passenger window? I catch male voices drifting toward me on the evening air. Heart pounding in my ears now - quiet, quiet, I order - I need to be able to hear and think. Try to steady breathing, better to concentrate. The truck is still approaching down the grassy track, bumping and swaying. I up the pace, pull down my baseball hat firmly and set my jaw sternly. I will my body harder, leaner, tauter, try to look focussed and 'don't mess with me'. Not for the first time, I wish my slight, 5'3" runner's body were somewhat more imposing. Suddenly breath-catchingly, the truck veers off the track a few metres in front of me. I hear loud male voices and a radio blaring. Heart still pounding out time. Just in case, as I up the pace to get out of the danger zone, I tack from side to side... in order to make myself a more difficult target.

Via sociological-phenomenological bracketing of my long experience of similar encounters resulting in verbal or physical harassment, the above response appears bizarre, unfounded and melodramatic. On the basis of experience, however, I cannot discount 24 years' running, and many more of being a woman moving in and through public space, which have honed my habit-body/mind. The challenges of attempting epochē are forcibly brought home to me. 


\section{Concluding - not conclusive - thoughts}

In this article, I have explored just some of the possibilities offered by sociologicalphenomenology for researching lived sporting-body experiences, and by feminist phenomenology for examining female sporting embodiment specifically. Commensurate with the phenomenological tradition, which emphasizes the incompleteness of all knowledge and understanding, I must emphasize that this account is of course very partial - because of my own specific characteristics (gender, age, socio-cultural location, ability etc), and because we can never capture or convey fully the essential structures of lived experience. We can only try our best to engage in the 'breathing of meaning' (van Manen 2000) and to share our lived experience. Likewise, feminist phenomenology provides just one of a myriad of different ways to research and represent women's sporting experience and embodiment. Importantly too, it is explicit about its standpoint and partialness. It seeks to generate accounts that locate the specifics of individual experience within broader social structures, including the gender order.

Sociological-phenomenology can provide not only a strong theoretical and methodological framework for examining human subjectivity and embodiment in general, but allied to feminism is particularly well-suited to the analytic task of charting women's lived-body sporting experiences and the specifics of socially-relating, gendered bodies within a particular social structure. In common with any theoretical and methodological approach, there are of course limitations, but feminist phenomenology's insistence on taking seriously, and remaining faithful to the phenomena portrayed in women's own experiential accounts, grounded in both the material-corporeal body and in a wider social-structural framework, provides a potent analytic framework. This form of phenomenology encourages reflection upon, and empathic understanding of, how it feels to be the woman in the lived sporting body; a body that is also, as sociology emphasizes, inscribed and imbued with socio-cultural meanings, significances, purposes and interests.

Word count: 7481 


\section{References}

Allen-Collinson, J. 2009. Sporting embodiment: Sports studies and the (continuing) promise of phenomenology. Qualitative Research in Sport and Exercise 1 (3): 279296.

Allen-Collinson, J. 2010. Running embodiment, power and vulnerability: Notes towards a feminist phenomenology of female running. In Women and Exercise: The Body, Health and Consumerism, edited by E. Kennedy and P. Markula (pp. 280-298). London: Routledge.

Allen-Collinson, J. 2011. Intention and epochē in tension: autophenomenography, bracketing and a novel approach to researching sporting embodiment. Qualitative Research in Sport \& Exercise 3 (1): 48-62.

Allen-Collinson, J. and J. Hockey. 2011 in press. Feeling the way: notes toward a haptic phenomenology of scuba diving and distance running. International Review for the Sociology of Sport.

Arnold, P.J. 1979. Meaning in movement, sport and physical education. London: Heinemann.

Bale, J. 2004. Running cultures. London: Routledge.

Bar-On Cohen, E. 2006. Kime and the moving body: Somatic codes in Japanese martial arts. Body \& Society 12 (4): 73-93.

de Beauvoir, S. 1972. The second sex (trans. H. Parshley). Harmondsworth: Penguin Books.

de Beauvoir, S. 2009. The second sex (trans. C. Borde and S. Malovany-Chevallier). London: Jonathan Cape.

Berger, P.L. and Luckmann, T. 1967. The social construction of reality. A treatise in the sociology of knowledge. Garden City, NY: Doubleday Anchor.

Butler, J. 2006. Sexual difference as a question of ethics: Alterities of the flesh in Irigaray and Merleau-Ponty. In Feminist interpretations of Maurice Merleau-Ponty, edited by 
D. Olkowski and G. Weiss (pp.107-125). University Park, PA: Penn State University Press.

Breivik, G. 2010. Being-in-the-void: A Heideggerian analysis of skydiving. Journal of Philosophy of Sport 37 (1): 29-46.

Chisholm, D. 2008. Climbing like a girl: An exemplary adventure in feminist phenomenology. Hypatia 23 (1): 9-40.

Crossley, N. 2001. The social body: Habit, identity and desire. London: Sage.

Csordas, T. 2002. Body/meaning/healing. New York: Palgrave Macmillan.

Drummond, J. J. 2007. Phenomenology: neither auto- nor hetero- be. Phenomenology and the Cognitive Sciences 6: 57-74.

Ehrich, L.C. 1999. Untangling the threads and coils of the web of phenomenology. Education Research and Perspectives 26 (2): 19-44.

Embree, L. and J. N. Mohanty. 1997. Introduction. In Encyclopaedia of Phenomenology edited by L. Embree et al. (pp. 1-10). Dordrecht: Kluwer Academic Publishers.

Finlay, L. 2009. Debating phenomenological research methods. Phenomenology \& Practice 3 (1): 6-25.

Fisher, L. 2000. Phenomenology and feminism: Perspectives on their relation. In Feminist phenomenology, edited by L. Fisher and L. Embree (pp.17-37). Dordrecht, Netherlands: Kluwer Academic Publishers.

Fisher, L. and L. Embree, eds. 2000. Feminist phenomenology. Dordrecht, Netherlands: Kluwer Academic Publishers.

Garfinkel, H. 1984. Studies in ethnomethodology, $2^{\text {nd }}$ revised edition. Cambridge: Polity Press.

Garfinkel, H. 2002. Ethnomethodology's program: Working out Durkheim's aphorism. New York: Rowman \& Littlefield.

Gearing, R. E. 2004. Bracketing in research: A typology. Qualitative Health Research 14 (10): 1429-1452. 
Giorgi, A. ed. 1985. Phenomenology and psychological research. Pittsburgh: Duquesne University Press.

Giorgi, A.P. 1997. The theory, practice and evaluation of the phenomenological method as a qualitative research procedure. Journal of Phenomenological Psychology 28 (2): 235-260.

Grosz, E. 1994. Volatile bodies: Toward a corporeal feminism. Bloomington: Indiana University Press.

Gruppetta, M. 2004. Autophenomenography? Alternative uses of autobiographically based research. In Association for Active Researchers in Education (AARE) Conference Paper Abstracts - 2004, edited by P. L. Jeffery. Sydney: AARE. Retrieved June 9, 2009, from: http://www.aare.edu.au/04pap/gru04228.pdf.

Hall, M. A. 1996. Feminism and sporting bodies: Essays on theory and practice. Champaign, Il: Human Kinetics.

Hanmer, J. and S. Saunders. 1984. Well-founded fear: A community study of violence to women. London: Hutchinson.

Heidegger, M. 1962. Being and time. Oxford: Blackwell.

Hemphill, D. 2005. Deeper inside the beautiful game. Journal of the Philosophy of Sport XXXII: $105-115$.

Hockey, J. and J. Allen-Collinson. 2007. Grasping the phenomenology of sporting bodies. International Review for the Sociology of Sport 42 (2): 115-131.

Hughson, J. and D. Inglis. 2002. Inside the beautiful game: Towards a Merleau-Pontian phenomenology of soccer play. Journal of the Philosophy of Sport XXIX: 1-15. Husserl, E. 1970. The crisis of European sciences and transcendental phenomenology (trans. D. Carr). Evanston, IL: Northwestern University Press.

Husserl, E. 1983. Ideas pertaining to a pure phenomenology and to a phenomenological philosophy: First book (trans. F. Kersten). Dordrecht: Kluwer Academic Publishers. Jennings, J.L. 1986. Husserl revisited: The forgotten distinction between psychology and phenomenology. American Psychologist 41 (11): 1231-1240. 
Katz, J. and T.J. Csordas. 2003. Phenomenological ethnography in sociology and anthropology. Ethnography 4 (3): 275-288.

Kerry, D.S. and K.M. Armour. 2000. Sport sciences and the promise of phenomenology: Philosophy, method, and insight. Quest 52 (1): 1-17.

Liberman, K. 2009. The itinerary of intersubjectivity in social phenomenological research. Schutzian research. A Yearbook of lifeworldly phenomenology and qualitative social science 1: 149-164.

Marbach, E. 2007. No heterophenomenology without autophenomenology: Variations on a theme of mine. Phenomenology and the Cognitive Sciences 6 (1-2): 75-87.

Martín Alcoff, L. 2000. Phenomenology, post-structuralism, and feminist theory on the concept of experience. In Feminist phenomenology, edited by L. Fisher and L. Embree (pp. 39-56). Dordrecht, Netherlands: Kluwer Academic Publishers.

Masciotra, D., E. Ackermann and W.-M. Roth. 2001. 'Maai': The art of distancing in Karate-Do: Mutual attunement in close encounters. Journal of Adult Development 8 (2): 119-132.

Maso, I. 2001. Phenomenology and ethnography. In Handbook of ethnography, edited by P. Atkinson, A. Coffey, S. Delamont, J. Lofland and L. Lofland (pp. 136-144). Thousand Oaks, CA: Sage,

Merleau-Ponty, M. 1963. The structure of behaviour (trans. A.L. Fisher). Boston: Beacon Press.

Merleau-Ponty, M. 1969. The visible and the invisible (trans. A. Lingis). Evanston, IL: Northwestern University Press.

Merleau-Ponty, M. 2001. Phenomenology of perception (trans. C. Smith). London: Routledge \& Kegan Paul.

Moe, V. F. 2004. How to understand skill acquisition in sport. Bulletin of Science, Technology \& Society 24 (3): 213-224.

Morley, J. 2001. Inspiration and expiration: Yoga practice through Merleau-Ponty's phenomenology of the body. Philosophy East and West 51 (1): 73-82. 
Mortari, L. and M. Tarozzi. 2010. Phenomenology as philosophy of research: An introductory essay. In Phenomenology and human science research today, edited by L. Mortari and M. Tarozzi (pp. 9-54). Bucharest: Zeta Books.

Olkowski, D. and G. Weiss, eds. 2006. Feminist interpretations of Maurice Merleau-Ponty. University Park, PA: Pennsylvania State University Press.

Preston, B. 1996. Merleau-Ponty and feminine embodied existence. Man and World 29 (2): 167-186.

Pringle, R. 2009. Defamiliarizing heavy-contract sports: A critical examination of rugby, discipline, and pleasure. Sociology of Sport Journal 26 (2): 211-234.

Psathas, G., ed. 1973. Phenomenological sociology: Issues and applications. London: John Wiley.

Reuter, M. (1999) Merleau-Ponty's notion of pre-reflective intentionality. Synthèse, 118: $69-88$.

Ryba, T. 2008. Researching children in sport: Methodological reflections. Journal of Applied Sport Psychology 20 (3): 334-348.

Samudra, J. K. 2008. Memory in our body: Thick participation and the translation of kinaesthetic experience. American Ethnologist 35 (4): 665-681.

Schutz, A. 1967. Phenomenology of the social world (trans. G. Walsh and F. Lehnert). Evanston, IL: Northwestern University Press.

Schutz, A. and T. Luckmann. 1973. The structures of the life-world: Volume 1. Evanston, IL: Northwestern University Press.

Smith, S.L. 2000. British nonélite road running and masculinity. A case of 'running repairs'? Men and Masculinities 3 (2): 187-208.

Spiegelberg, H. 1982. The phenomenological movement. $3^{\text {rd }}$ and revised edition. Dordrecht: Martinus Nijhoff.

Spurling, L. 1977. Phenomenology and the social world. The philosophy of MerleauPonty and its relation to the social sciences. London: Routledge \& Kegan Paul. 
Sutton, J. 2007. Batting, habit and memory: The embodied mind and the nature of skill. Sport in Society 10 (5): 763-786.

Valentine, G. 1989. The geography of women's fear. Area 21: 385-390.

Van Manen, M. 2000. Professonal practice and 'doing phenomenology'. In Handbook of Phenomenology and Medicine, edited by S. K.Toombs. London: Kluwer Academic Publishers.

Wacquant, L. 2004. Body and soul: Notebooks of an apprentice boxer. Oxford: Oxford University Press.

Wagner, H. R. 1973. The scope of phenomenological sociology: Considerations and suggestions. In Phenomenological sociology: Issues and applications, edited by G. Psathas (pp. 61-87). London: John Wiley.

Wearing, B. 1998. Leisure and feminist theory. London: Sage.

Whitehead, M. 2007. Physical literacy: Philosophical considerations in relation to developing a sense of self, universality and propositional knowledge. Sport, Ethics and Philosophy 1 (3): 281-298.

Willig, C. 2008. Introducing qualitative research in psychology. $2^{\text {nd }}$ ed. Milton Keynes: Open University Press/McGraw Hill.

Young, I.M. 1980. Throwing like a girl: A phenomenology of feminine body comportment, motility and spatiality. Human Studies 3 (2): 137-156.

Young, I.M. 1998. 'Throwing like a girl': Twenty years later. In Body and flesh: $A$ philosophical reader, edited by D. Welton (pp. 286-290). Oxford: Blackwell. 